\title{
Didática da Geografia a partir das orientações metodológicas presentes no curso de formação de professores da FFCL da USP (1934-1960)
}

\begin{abstract}
Márcia Cristina de Oliveira Mello ${ }^{1}$
1 Docente do Curso de Geografia da Universidade Estadual Paulista (UNESP); Fundação de Amparo à Pesquisa do Estado de São Paulo (FAPESP) Processos n. 2014/01139-5 e n. 2021/01155-4, Brasil | marcia.mello@unesp.br; | https://orcid.org/0000-0001-8517-3901

Resumo: Na pesquisa concluída anteriormente "Orientações metodológicas destinadas aos professores de Geografia para o ensino secundário da escola paulista (1934-1960)" destacamos as primeiras impressões sobre o papel fundamental que o curso da USP desempenhou para promover o que hoje entendemos sobre a prática do ensino de Geografia, especialmente por meio da participação na organização interna da Didática da Geografia em nosso país. Do seleto grupo de professores formados pela Faculdade de Filosofia, Ciências e Letras (FFCL) da USP, entre as décadas de 1930 e 1960, surgiu uma geração de brilhantes geógrafos docentes, dentre eles destacaremos, na continuidade da pesquisa, a figura da professora Amélia Americano Domingues de Castro. A professora Amélia foi pioneira nesta área e se destacou por introduzir as ideias de Jean Piaget no curso de formação inicial docente em Geografia. Certamente a matriz caracterizada pela orientação escolanovista da época teve inúmeras variáveis, cujas versões é preciso ainda investigar para compreendermos o presente e as múltiplas angústias do pensar o como "fazer" o ensino de Geografia nas escolas. Neste sentido, temos como objetivos identificar e compreender aspectos da Didática da Geografia constituída no contexto da Escola Nova, a partir das orientações contidas no Curso de formação de professores de Geografia da FFCL da USP, ampliando conhecimentos sobre a contribuição da professora Amélia à Didática da Geografia, no que se refere a sua matriz escolanovista e piagetiana, por meio da análise das orientações metodológicas que estruturaram o seu pensamento, articuladamente aos elementos da prática pedagógica: o aluno (que aprende); o professor; e o conhecimento geográfico.
\end{abstract}

Palavras-chave: Didática da Geografia; Formação de Professores; Didática da Escola Nova.

Geography Didactics from the Methodological Guidelines in the USP FFCL Training Course (1934-1960)

Abstract: In the previously completed research, "Methodological Guidelines Selected for Geography teachers for the Middle School of the São Paulo School (1934-1960)" stand out the first impressions about the fundamental role that the USP course performed in promoting what we understand nowadays about the practice of teaching geography, especially through the internal organization of Geography Didactics. From the select group of professors graduated from USP's Faculty of Philosophy, Sciences, and Letters (FFCL), between the 1930 s and 1960s, a generation of brilliant teaching geographers emerged, among them we highlight, in the continuity of the research, the figure of professor Amélia Americano Domingues de Castro. Professor Amelia was a pioneer in this area and stood out for introducing Jean Piaget's ideas in the initial teacher training course in Geography. Certainly the matrix characterized by the Escanovist orientation of the time had numerous variables, whose versions still need to be investigated in order to understand the present and the multiple anxieties of thinking and how to "do" the teaching of geography in schools. In this sense, we aim to identify and understand aspects of the Geography Didactics constituted in the context of the Escola Nova, from the orientations contained in the USP FFCL Geography Teacher Training Course, expanding knowledge about the contribution of Professor Amelia to Didactics of Geography, in what refers to its scholovist and piagetian matrix through the analysis of the methodological orientations that structured its thinking in articulation with the elements of the pedagogical practice: the student (who learns); the teacher and the geographical knowledge.

Keywords: Geography Didactics; Teacher Training; Escola Nova Didactic. 


\section{Introdução}

A partir dos resultados da pesquisa intitulada "Orientações metodológicas destinadas aos professores de Geografia para o ensino secundário da escola paulista (1934-1960)" observamos que as características do primeiro curso de formação docente em Geografia [e História], em nível superior oferecido pela Universidade de São Paulo (USP), permitem compreender determinadas "matrizes" de ordenação do campo profissional docente em Geografia. Uma das matrizes está atrelada à Didática da Escola Nova.

Na pesquisa concluída anteriormente ressaltamos as primeiras impressões sobre o papel fundamental que o curso da USP desempenhou para promover o que hoje entendemos sobre a prática do ensino de Geografia, especialmente por meio da organização interna da Didática da Geografia, enquanto um conjunto de ideias, processos, formas e conteúdos fundamentados nos pressupostos psicológicos da aprendizagem (a inovação educacional que redescobriu a criança), validados cientificamente pela Pedagogia científica, incluindo a Psicologia da Educação.

Do seleto grupo de professores formados pela Faculdade de Filosofia, Ciências e Letras (FFCL) da USP, entre as décadas de 1930 e 1960, surgiu uma geração de brilhantes geógrafos docentes, dentre eles destacamos a figura da professora Amélia Americano Domingues de Castro (1920-2020), dada sua proximidade com a Didática da Geografia [e das Ciências humanas].

A professora Amélia por ser pioneira nesta área se destacou por introduzir as ideias de Jean Piaget no curso de formação inicial docente em Geografia, portanto, esta será nossa preocupação na continuidade da pesquisa, já que não foi possível explorá-la devidamente no momento anterior.

Certamente a matriz caracterizada pela orientação escolanovista da época teve inúmeras variáveis, cujas versões é preciso ainda investigar para compreendermos o presente e as múltiplas angústias do pensar o como "fazer" o ensino de Geografia nas escolas. Assim, entender como a Didática da Geografia foi pensada e constituída no passado recente, de forma acadêmica e sistematizada, pode nos auxiliar na compreensão dos problema enfrentados na atualidade.

Desta forma, o problema a ser tratado envolve entender como a Didática da Escola Nova, contida nas orientações metodológicas destinadas aos professores do curso de formação docente da USP, influenciou o campo pedagógico da Geografia. Supomos que aquelas bases podem estar presentes até os dias de hoje para o ensino de Geografia.

\section{Resultados}

\subsection{Didática da Geografia e Escolanovismo}

As bases didático-pedagógicas das ideias escolanovistas fundaram um modo de pensar o ensino de Geografia que impulsionou tanto a produção do conhecimento na área, quanto motivaram a constituição de orientações destinadas aos professores, centradas nas ideias de Jean Piaget.

Um forte indício para isto detectamos em conversa com a professora Amélia quando nos relatou em entrevista (Mello, 2017) que ela própria quando ingressou na USP, como auxiliar de ensino e depois docente da FFCL, tinha uma preocupação maior que era o como "ensinar a ensinar" o futuro professor da área das Ciências humanas. Como então, na época a literatura estrangeira sobre Didática indicava que Jean Piaget era um caminho importante para esta questão, a professora Amélia encontrou no mestre Piaget, e em sua obra, algumas respostas sobre a questão do processo de ensino-aprendizagem (na verdade mais sobre a aprendizagem) dos conceitos geográficos. 
$\mathrm{Na}$ época a bibliografia disponível era insuficiente, assim a professora Amélia fazia a tradução livre dos textos de Jean Piaget, que não estava toda ainda à disposição na USP, fato que obrigava Amélia a se deslocava até a biblioteca da Faculdade Makenzie para emprestar os livros. Os exercícios de leitura e tradução das ideias de Piaget permitiam a professora Castro elaborar textos para as aulas de Didática do curso da USP e disseminar algumas ideias importantes do psicólogo suíço sobre o processo de desenvolvimento da aprendizagem por parte, dos alunos.

De certa forma ela percebeu que:

O construtivismo, desde sua fonte e matriz teórica identificadas na obra de Piaget, mantém forte afinidade com o escolanovismo. Podemos, mesmo, considerar que se encontra aí a teoria que veio dar base científica para o lema pedagógico "aprender a aprender". Efetivamente, o próprio Piaget em vários de seus trabalhos [...] se reporta ao escolanovismo e chega, inclusive, a considerar que os princípios dos métodos novos podem ser encontrados nos grandes clássicos da pedagogia desde a Antiguidade, porém de modo intuitivo. O que vai distinguir a postulação escolanovista desses métodos em relação às formulações anteriores é a busca de base científica, a qual só será encontrada com a formulação da psicologia da infância [...]. E a psicologia genética elaborada por Piaget em suas investigações epistemológicas emergirá como o ponto mais avançado da formulação científica da Escola nova no que se refere às bases psicopedagógicas do processo de aprendizagem. (Saviani, 2010, p. 434).

A Didática escolanovista neste contexto foi articulada com as bases da Psicologia científica, representado especialmente por Manuel Bergström Lourenço Filho (1897-1970) e Noemy da Silveira Rudolfer (1902-1980). Protagonistas do movimento escolanovista eles colocaram em prática o projeto de reformulação pedagógica que revelava a necessidade de uma teoria de largo alcance de revisão crítica apontando novas concepções sobre sociedade, homem, criança/aluno, e consequentemente, sobre o ensino e sobre a aprendizagem.

A nova concepção de aluno tinha em vista promover o desenvolvimento "natural" do educando, possibilitando a sua "formação da personalidade", o que poderia alterar todo o aspecto interno da Didática.

A Didática da Escola Nova, então, foi se apropriando da concepção piagetiana de educando e do novo conceito de aprendizagem baseando-se nos interesses e necessidades da criança, em que o importante não era aprender coisas, mas aprender a observar, a pesquisar, a pensar, enfim "aprender a aprender".

O conceito de aprendizagem substituiu a idealização dos métodos em detrimento aos aspectos psicológicos da aprendizagem. Desta forma, aprendizagem por parte dos alunos e medida do aprendizado escolar passaram a permear os saberes necessários à prática de ensino. Isto fez com o curso da USP também se adequasse a esta premissa.

$\mathrm{Na}$ época a Didática era um Curso da USP e também disciplina implantada pelo artigo 20 do Decreto Lei n. 1190/39. Assim, a cadeira de Didática Geral e Especial da FFCL da USP foi criada em 1939. A partir de 1940 aparecem os primeiros formados no Curso de Didática.

Segundo Veiga (1995) a Didática era considerada no período entre as décadas de 1930 e 1940 enquanto um conjunto de concepções que reuniam uma tradição humanista tradicional e outra humanista moderna. "[...] a concepção humanista moderna se baseia em uma visão de homem centrada na existência, na vida e na atividade." (p. 30). Como características desta Didática tem-se: a valorização da criança; o incentivo a liberdade, a iniciativa e autonomia das crianças; e o respeito as características individuais dos alunos.

Dada a importância à criança e seus aspectos psicológicos, os problemas da escola passaram a ser considerados pela questão escolar e técnica, com ênfase em ensinar bem "[...] a Didática também sofre a influência, passando a acentuar o caráter prático-técnico do processo ensino-aprendizagem, onde teoria e prática são justapostas." (Veiga, 1995, p. 31). 
Assim, os métodos e técnicas mais difundidos no curso da USP foram os centros de interesse; o estudo dirigido; as unidades didáticas; os métodos de projetos; as fichas didáticas; o contrato de ensino; a excursões geográficas; e o estudo do meio.

A Didática enquanto disciplina e Curso teve vigência até 1946, quando o Decreto Lei $\mathrm{n}$. 9053, de 1946 desobrigou o Curso de Didática, mudando o esquema de formação conhecido como três mais um. A partir da Lei de Diretrizes e Bases n. 4024, de 1961, a Didática perdeu as caracterizações de Geral e Especial para ser substituída por Prática de Ensino sob a forma de Estágio Supervisionado.

O Curso da USP tentou superar a tendência tradicional da Didática, já que desde o início percebe-se o alinhamento com a tendência renovada da Didática quando cumpriu ao grupo da USP renová-la por meio dos programas da disciplina de Metodologia do ensino secundário, substituída em seguida por Didática.

De acordo com Garcia (1995, p. 82), quando o curso de Didática e a disciplina de Didática foram institucionalizadas nas Faculdades de Filosofia, Ciências e Letras para atender ao decreto lei n. 1.190, de 4 de abril de 1939:

O seu estatuto epistemológico nesses anos oscila entre a arte e a ciência, e os seus conteúdos são um amálgama de temas e discussões buscados naquelas áreas de conhecimento, entre os quais vai se destacando um conteúdo de caráter técnico e metodológico que pretendia dar conta dos problemas do ensino e da aprendizagem de qualquer matéria e nível de ensino.

A constituição inicial do curso de Didática era composta das seguintes disciplinas: Didática Geral; Didática Especial; Psicologia educacional; Administração educacional; Fundamentos biológicos da educação; e Fundamentos sociológicos da educação. Desde 1939 a cadeira de Didática Geral e Especial foi organizada na FFCL da USP contendo um plano de trabalho desenvolvido em duas partes; a primeira denominada teórica - a cargo de um professor catedrático responsável pela Didática Geral; a segunda denominada de prática - a cargo dos professores auxiliares, abrangendo, então as Didáticas Especiais.

Sobre a atuação dos professores da disciplina de Didática destacamos a atuação da exaluna do curso e professora do curso - Amélia Americano Domingues de Castro - que foi contratada, em 1942, como professora substituta da disciplina. Doutorou-se em 1950, orientada por Noemy da Silveira Rudolfer. Em sua atuação e produção intelectual se preocupou com os temas relativos aos processos didáticos: as bases psicológicas da aprendizagem; a exposição do assunto; a direção da aprendizagem; seleção e uso do material de ensino; e a verificação do aprendizado.

Certamente autores como Dewey contribuíram de forma marcante para a divulgação dos princípios escolanovistas, cuja noção central era o conceito de experiência, que seria a educação pela ação da criança. Assim, a escola centrada na criança (aluno) deveria favorecer a um espaço para o desenvolvimento de seus interesses. "Por isso, vidaexperiência-aprendizagem não se separam, e a função da escola é possibilitar a reconstrução continuada que a criança faz da experiência." (Aranha, 2006, p. 261).

No entanto, Dewey e outros representantes da Escola Nova não traziam a explicação sobre o universo da aprendizagem infantil.

Naquele momento o pressuposto epistemológico sobre a unidade dialética da teoria e da prática já superava a visão positivista e caminhava para o que hoje conhecemos como visão dialética da conexão entre teoria-prática. Um fator que contribuiu para isto foi a revolução coperniana sobre a concepção de criança, o sujeito cognoscente de Jean Piaget. A partir dali para se pensar todo ato pedagógico era necessário conhecer as característica psicológicas do aluno em sua aprendizagem, o que poderia mudar os paradigmas de ensino, a saber: do privilégio da memorização para a curiosidade do sujeito cognoscente; da cópia do texto do manual de ensino para a pesquisa como atividade inerente ao processo de ensino-aprendizagem; e da certeza da eficiência do aparato metodológico para a pesquisa como possibilidade de ensino. 
A produção intelectual da professora Amélia foi fortemente influenciada por Jean Piaget, nos levando a concluir que ela encontrou no psicólogo suíço o referencial teórico adequado para a época. Amélia nos relatou que o problema inicial para ela era pensar em como ensinar a ensinar, e, a partir de Piaget ela obteve uma pronta resposta.

Para ela este foi o ponto fundamental para a Didática da Geografia. A partir dali as atividades de ensino deveriam ser escolhidas a partir da teoria ampla e complexa formulada por Piaget sobre o processo de construção do conhecimento, em que as crianças aprendem por experiência cada vez mais complexas, que partem do concreto para o abstrato, passando por etapas ou fases do desenvolvimento intelectual.

Assim, cada criança reproduziria, pela ontogênese, nas grandes linhas a filogênese, ou seja, o conhecimento geográfico produzido pela humanidade. Na nossa interpretação esta foi a maior contribuição da professora Amélia para a Didática da Geografia, que mais tarde influenciou a produção sobre a cartografia escolar, ou o estudo cognitivo do mapa, a citar a tese da professora Lívia de Oliveira, baseada toda nas provas piagetianas (Oliveira, 1977).

Dada a importância da professora Amélia, buscaremos destacar identificar e compreender de forma sistemática aspectos da Didática da Geografia constituída no contexto da Escola Nova.

A professora Amélia Americano Domingues de Castro nasceu em 27 de dezembro de 1922, no Rio de Janeiro. Filha do oficial Severino Ribeiro Franco, casou-se com Luiz Domingos de Castro, com quem teve três filhos. Realizou seus estudos de educação básica no Rio de Janeiro. Posteriormente mudou-se para São Paulo onde ingressou no curso de Geografia e História da FFCL da USP.

Quando professora da cadeira de Didática Geral e Especial, da FFCL da USP, apresentou, em 14 de outubro de 1950, a tese de doutorado orientada pela renomada professora Noemy da Silveira Rudolfer. Estudou aspectos dos processos didáticos, princípios dos métodos envolvendo seus aspectos psicopedagógicos e suas relações com o ensino secundário.

Em 1954 era Professora Assistente do professor Onofre de Arruda Penteado Júnior, da Cadeira de Didática Geral e Especial, momento que se tornou responsável pela Didática Especial da Geografia (USP, 1954). O professor Onofre certamente tinha uma afinidade com a Didática da Geografia, já que escreveu o manual de ensino Metodologia da Geografia, publicado em 1928.

\section{Metodologia}

Ao desenvolver a pesquisa de abordagem histórica utilizamos procedimentos de localização, organização e análise de fontes documentais primárias e secundárias. As fontes foram categorizadas da seguinte forma:

\section{1 Fontes Relacionadas às Orientações Didáticas Contidas no Curso da FFCL da USP (1934-1960)}

Com destaque ao texto da professora Amélia Americano Domingues de Castro Didática: perspectivas deste século (Versão em artigo da apostila utilizada pela professora Amélia nas primeiras aulas de Didática da Geografia). Ainda as contidas nos programas de ensino do curso de Didática Especial de Geografia; - nos documentos produzidos pelos sujeitos que estruturaram a Didática da Geografia na época; e nos relatos de experiência dos professores do curso ou professores da escola secundária, publicados em formato de artigos nas revistas da época como Geografia, Boletim Paulista de Geografia e Boletim Geográfico. 
Nesta categoria serão privilegiadas as seguintes fontes:

Mello, M. C. O. (2017). Entrevista concedida por Amélia Americano Domingues de Castro. (Manuscrito não publicado).

Nadai, E. (1991). A educação como apostolado: histórias e reminiscências (São Paulo 1930-1970). Tese de livre-docência, Universidade de São Paulo. São Paulo, Brasil.

Nadai, E. (1994). Fernando de Azevedo e a formação pedagógica do professor secundário: o instituto de educação. Revista da Faculdade de Educação, 172, 151172.

Universidade de São Paulo (USP). (1953). Faculdade de Filosofia, Ciências e Letras. Cadeira de Didática Geral e Especial. Anuário da Faculdade de Filosofia, Ciências e Letras 1939-1949, 429-431.

Universidade de São Paulo (USP). (1954). Faculdade de Filosofia, Ciências e Letras. Didática Especial da Geografia. Programas aprovados pela Congregação para o ano letivo de 1954, 424-426.

Universidade de São Paulo (USP). (1959). Faculdade de Filosofia, Ciências e Letras. Didática Especial da Geografia. Programas aprovados pela Congregação para o ano letivo de 1959, 329-331.

Universidade de São Paulo (USP). (1960). Faculdade de Filosofia, Ciências e Letras. Didática Especial da Geografia. Programas aprovados pela Congregação para o ano letivo de 1960, p. 335-337.

\subsection{Fontes Relacionadas ao Campo da Didática}

Nesta categoria entre as fontes privilegiadas temos:

Castro, A. A. D. et al. (1975). Didática da escola média: teoria e prática. São Paulo: Edibell.

Castro, A. A. D. (1975). Didática: perspectivas deste século. Revista da Faculdade de Educação, 1, 63-83.

Lourenço Filho, M. B. (1945). Prática de ensino. Arquivos do Instituto de Educação, 2(4), 33-42.

Lourenço Filho, M. B. (1930). A “Escola nova”. Escola Nova, 1(1), 3-7.

\subsection{Fontes Relacionadas ao Campo da Didática da Geografia}

Entre as fontes privilegiadas temos:

Carvalho, C. M. D. (1925). Methodologia do ensino geographico: introducção aos estudos de Geographia moderna. Rio de Janeiro: Francisco Alves.

Carvalho, C. M. D. (1956). Didática da Geografia. Boletim Geográfico, 131, 522-524.

Monbeig, P., Azevedo, A. de \& Carvalho, M. C. V. (1935). O ensino secundário da Geografia. Geografia, 4, 77-82.

Monbeig, P. (1945). A Geografia no Ensino secundário. Boletim geográfico, 26, 163-171.

Proença, A. F. (1928). Como se ensina Geographia. São Paulo: Melhoramentos.

\subsection{Fontes Relacionadas ao Escolanovismo e ao Construtivismo Piagetiano}

Buscaremos as fontes privilegiadas ao tema nesta categoria, com auxílio da equipe executora incluindo alunos da Graduação em Geografia, considerando o levantamento da produção da professora Amélia Americano Domingues de Castro sobre Piaget e a Didática da Geografia. Aqui destaca-se o estudo da professora Lívia de Oliveira, e a apropriação que ela fez do construtivismo piagetiano. Ela foi aluna do curso da USP e se formou em 1958. (Oliveira, L. (1977). Estudo metodológico e cognitivo do mapa. Tese de livre docência, Universidade Estadual Paulista. Rio Claro, Brasil. 


\section{Conclusões}

Amélia de Castro se tornou uma especialista em métodos e práticas de ensino, uma metodóloga. Ao se especializar nesta área preocupou-se com os fundamentos técnicopedagógicos e psicológicos dos métodos de ensino. Na época o campo se preocupava em relacionar a tríade conteúdos, objetivos de ensino e educando, assim como a sua aplicabilidade na escola secundária.

Em 1975 publicou Didática: perspectivas deste século, pela Revista da Faculdade de Educação, da USP. Trata-se da versão ampliada e revisada de um texto em formato de apostila que a professora usava nas aulas de Didática da USP. Enquanto metodóloga se preocupava com a Didática para além das orientações de práticas escolares, tomando-a também um objeto de estudo. A professora Amélia faleceu recentemente, em 2020, deixando seu legado à Didática, especialmente no que se refere a sua matriz escolanovista e piagetiana.

\section{Agradecimentos}

Agradeço ao apoio FAPESP - Processos n. 2014/01139-5 e n. 2021/01155-4, Fundação de Amparo à Pesquisa do Estado de São Paulo.

\section{Referências}

Aranha, M. L. A. (2006). História da Educação e da Pedagogia: geral e Brasil. 3a. ed. São Paulo: Moderna.

Batista, D. E. (2017). A didática de Comênio: entre o método de ensino e a voz viva do professor. Pro-posições, 28, 256-276.

Cacete, N. H. (2003). A formação de professores para escola secundária e sua localização institucional: da faculdade de filosofia ao Instituto superior de educação. Tese de doutorado Programa de Pós-graduação em Geografía, Universidade de São Paulo. São Paulo, Brasil.

Cacete, N. H. (2014). Breve história do ensino superior brasileiro e da formação de professores para a escola secundária. Educação e Pesquisa, 40(4), 1-16.

Cacete, N. H. (2015). Formação do professor de Geografia: sobre práticas de ensino e estágio supervisionado. Revista Casa da Geografia, 17(2), 3-11.

Candau, V. M. \& Lelis, I. A. (1993). A relação teoria-prática na formação do educador. In Candau, V. M. (Ed.), Rumo a uma nova Didática (pp.49-63). Petrópolis: Vozes.

Castro, A. A. D. (1975). Didática: perspectivas deste século. Revista da Faculdade de Educação, 1 , 63-83.

Comenius, I. A. (2001). Didactica Magna (Tradução de Joaquim Ferreira Gomes). Fundação Calouste Gulbenkian. (Versão para ebooks Brasil.org).

Garcia, M. M. A. (1995). O campo da Didática no ensino superior: um enfoque sócio-histórico. Educação \& realidade, 20, 73-91.

Mello, M. C. O. (2007). Emilia Ferreiro e a alfabetização no Brasil: um estudo sobre a psicogênese da língua escrita. São Paulo: UNESP.

Mello, M. C. O. (2014). Os manuais de ensino de Geografia produzidos no primeiro terço de século XX: fontes e objetos de estudo. Revista brasileira de educação em Geografia, 4(8), 146-159.

Mello, M. C. O. (2017). Entrevista concedida por Amélia Americano Domingues de Castro. (Manuscrito não publicado). 
Monarcha, C. (1992). As três fontes da Pedagogia científica: a Psicologia, a Sociologia e a Biologia. Didática, 28, 41-49.

Nadai, E. (1991). A educação como apostolado: histórias e reminiscências (São Paulo 1930-1970). Tese de livre-docência, Programa Universidade de São Paulo. São Paulo, Brasil.

Oliveira, L. (1977). Estudo metodológico e cognitivo do mapa. Tese de livre docência, Universidade Estadual Paulista. Rio Claro, Brasil.

Pereira, D. A. C. (1989). Origens e consolidação da tradição didática na Geografia escolar brasileira. Dissertação de mestrado, Programa de Pós-graduação em Geografía, Universidade de São Paulo. São Paulo, Brasil.

Saviani, D. (2010). História das ideias pedagógicas no Brasil. 3a.ed. rev. Campinas: Autores Associados.

Universidade de São Paulo (USP). (1953). Faculdade de Filosofia, Ciências e Letras. Cadeira de Didática Geral e Especial. Anuário da Faculdade de Filosofia, Ciências e Letras 1939-1949, 429-431.

Universidade de São Paulo (USP). (1954). Faculdade de Filosofia, Ciências e Letras. Didática Especial da Geografia. Programas aprovados pela Congregação para o ano letivo de 1954. São Paulo, 424-426.

Veiga, I. P. A. (1995). Didática: uma retrospectiva histórica. In Veiga, I. P. A (Ed.), Repensando a Didática. 10a. ed. (pp. 25-40). Campinas: Papirus. 